\title{
Developmental Effects of Hypoxia and Indomethacin on Distribution of Vascular Resistances in Lamb Lungs
}

\author{
JOHN B. GORDON, JOHN HORTOP, AND TAWFIC S. HAKIM ${ }^{1}$ \\ The Montreal Children's Hospital and McGill University Departments of Pediatrics and Physiology, \\ Montreal, Quebec, Canada
}

\begin{abstract}
The influence of postnatal age on the distribution of vascular resistances was studied in in situ, isolated, blood perfused lungs of lambs aged 6-12 h, 2-4 d, 2 wk, and 1 mo. The pressure gradients across the upstream, downstream, and compliant middle segments were determined by an inflow-outflow occlusion technique during mild hyperoxia $\left(\mathrm{FIO}_{2}=0.28\right)$ and severe hypoxia $\left(\mathrm{FIO}_{2}=0.04\right)$ under control and indomethacin-treated conditions. The greatest response to hypoxia was seen in the middle segment. A lesser, but significant response was also seen in the upstream segment. Indomethacin accentuated the hypoxic response of the total circuit and the middle segment at all ages, and the upstream segment in the two younger age groups. An age-dependent increase in total hypoxic reactivity was seen in control lungs, but not in indomethacin-treated lungs. When the pressure gradient across the middle segment alone was considered, an age-dependent increase in hypoxic reactivity was seen in controls and a decrease was seen in indomethacin-treated lungs. In contrast there were no age-dependent changes in the hypoxic responses of the upstream or downstream segments. These data suggest that the predominant site of hypoxic pulmonary vasoconstriction and dilator prostaglandin activity lies within the middle gradient in newborn lamb lungs. Furthermore, the age-dependent changes in the hypoxic response of the middle gradient appear to be altered by the modulating influence of dilator prostaglandins. (Pediatr Res 26:325-329, 1989)
\end{abstract}

\section{Abbreviations}

HPV, hypoxic pulmonary vasoconstriction

PVR, pulmonary vascular resistance

PG, prostaglandin

Paw, tracheal pressure

Ppa, Pulmonary artery pressure

Pla, left atrial pressure

$\mathrm{FIO}_{2}$, fractional inspired oxygen

Q, constant flow

LSD, least significant different test

$\Delta \mathrm{Pm}$, middle segment gradient

$\Delta \mathrm{Pt}$, total pressure gradient

$\Delta \mathrm{Pa}$, upstream gradient

$\Delta \mathbf{P v}$, downstream gradient

Received October 19, 1988; accepted June 5, 1989.

Correspondence Dr. John B. Gordon, Director, Pediatric Intensive Care Unit, The Montreal Children's Hospital, Room D-765, 2300 Tupper, Montreal, Quebec, H3H 1P3, Canada.

Supported by the Quebec Heart Foundation and the McGill University/Montreal Children's Hospital Research Institute.

${ }^{1}$ Present address Department of Surgery, SUNY Health Science Center, Syracuse, NY 13210
It has long been established that normoxic PVR decreases rapidly after birth (1-3). In contrast, although some studies have shown that the vigor of HPV also decreases (3-5), others have indicated that HPV increases with age (6-11). In piglets the increase in hypoxic reactivity was positively correlated with the peripheral extension of arteriolar muscularization $(9,10)$ suggesting that arterioles might be the site of HPV. However, other newborn studies suggested that veins, not arterioles are the site of HPV (12-14). Moreover, in a previous study we found that dilator PG appeared to modulate HPV more in isolated lungs of 2- to 4-d than 2-wk-old lambs, suggesting that factors other than vascular muscularization may also influence the age-dependent changes in HPV (8).

In this study we examined the effects of hypoxia $\left(\mathrm{FIO}_{2}=0.04\right)$ on the distribution of pulmonary vascular resistances in isolated lamb lungs under control and indomethacin-treated conditions at four ages during the 1 st mo of life. We used an inflow-outflow occlusion technique to partition the pulmonary vascular circuit into relatively noncompliant upstream and downstream segments and a compliant middle segment $(11,15-17)$. The goals of our study were: 1 ) to identify the functional site of HPV by determining the segment most responsive to hypoxia, 2) to determine which segment(s) responds to indomethacin, and 3) to determine whether the responses to hypoxia and/or indomethacin are age dependent.

\section{MATERIALS AND METHODS}

Preparation. The in situ, isolated, blood perfused lungs of 39 newborn lambs were studied using an isolated lung preparation and occlusion technique previously described $(8,11)$. Each lamb was anesthetized with ketamine ( $50 \mathrm{mg} / \mathrm{kg}$ intramuscularly) after which a femoral artery and vein were cannulated and a tracheostomy tube was inserted. The lamb was paralyzed (pancuronium bromide $0.1 \mathrm{mg} / \mathrm{kg}$, intravenously) and ventilation initiated with a hyperoxic gas mixture. Heparin (3000-5000 U, intravenously) was administered via the femoral venous line and the lamb was rapidly exsanguinated. A median sternotomy was performed, the ductus arteriosus was ligated, and the pulmonary artery was cannulated via the right ventricular outflow tract. The left ventricle was excised and a large bore cannula was placed in the left atrium via the mitral valve. This was tightly secured just above the entry of the pulmonary veins into the atrium minimizing redundant atrial tissue below the cannula so that the contribution of the left atrium to pulmonary vascular compliance was negligible. The perfusion system was connected to the cannulae, the lungs were hyperinflated, and after removing all air from the perfusion system, flow was initiated.

The perfusate (autologous blood and 3\% dextran in Ringer's lactate) was pumped (Fisher, Manostat, New York, NY) from a reservoir to a heat exchanger (Travenol, pediatric miniprime, 
Travenol Canada, Ville St. Laurent, Quebec, Canada), bubble trap/particulate filter, and a flow probe (Carolina, EP 300A Carolina Medical Electronics, King, NC) then to an occluder from which it could be directed either to the pulmonary artery or directly back to the reservoir. Perfusate that entered the pulmonary artery exited the lungs through the left atrium to the reservoir that could be raised or lowered to achieve the desired Pla. Ppa, Pla, and Paw were zero referenced to the top of the lungs and constantly measured (Statham Gould P23id, Gould Inc. Medical Products Oxnard, CA). Q was measured (Carolina, model 501) and pressures and Q were constantly recorded (Grass Polygraph, model 701, Grass Inst. Co., Quincy, MA). After exsanguination, ventilation (Harvard model 613, Harvard Apparatus, S. Natick, MA) was established at $14-16.5 \mathrm{~mL} / \mathrm{kg}$ (body wt) tidal volume, a rate of $10 / \mathrm{min}$ and end expiratory pressure of $3 \mathrm{~mm} \mathrm{Hg}$. The gas mixtures were either slightly hyperoxic $\left(\mathrm{FIO}_{2}=0.28, \mathrm{CO}_{2} 5.5 \%\right.$, balance $\left.\mathrm{N}_{2}\right)$ or severely hypoxic $\left(\mathrm{FIO}_{2}\right.$ $=0.04, \mathrm{CO}_{2} 5.5 \%$, balance $\mathrm{N}_{2}$ ). This level of hypoxia has been found to cause a maximal pressor response in isolated lungs of lambs (8). Inspired $\mathrm{FIO}_{2}$ was constantly monitored (Amitek $\mathrm{O}_{2}$ analyzer, Amitek, Pittsburgh, PA). Perfusate hematocrit was between 15 and $17 \%$ and did not change during the experiment. Perfusate temperature was maintained between 38.5 and $39.5^{\circ} \mathrm{C}$. Initial blood glucose concentrations were $80-120 \mathrm{mg} / 100 \mathrm{~mL}$ and were maintained at this level by the addition of $50 \%$ dextrose during the study. Perfusate gases were verified at each $\mathrm{FIO}_{2}$ and $\mathrm{pH}$ was maintained between 7.33 and 7.45 by the addition of 1 $\mathrm{N} \mathrm{NaHCO}_{3}$.

Study groups. In all studies the distribution of vascular resistances was determined at $\mathrm{FIO}_{2}=0.28$ and 0.04 . A total of 26 studies was performed using control lungs from four age groups $(6-12 \mathrm{~h}, n=5 ; 2-4 \mathrm{~d}, n=6,12-16 \mathrm{~d}(2 \mathrm{wk}), n=6 ; 26-35 \mathrm{~d}(1$ $\mathrm{mo}), n=9)$. Twenty-six studies were also performed in indomethacin treated lungs from the four age groups $(6-12 \mathrm{~h}, n=5$; $2-4 \mathrm{~d}, n=6 ; 2 \mathrm{wk}, n=7 ; 1 \mathrm{mo}, n=8)$. In 13 of the 26 indomethacin studies, the drug was added at the beginning of perfusion whereas in the other 13 it was added after completing a control study (four at $6-12 \mathrm{~h}$, three at $2-4 \mathrm{~d}$, three at $2 \mathrm{wk}$, three at $1 \mathrm{mo})$. In all cases indomethacin $(40 \mu \mathrm{g} / \mathrm{mL}$ perfusate) was added to the reservoir. This dose had previously been shown to inhibit cyclooxygenase activity in this blood perfused preparation (8).

Protocol. After completing the surgical preparation $(<17 \mathrm{~min}$ of absent pulmonary blood flow), ventilation with the hyperoxic gas mixture and perfusion at a Pla $<0 \mathrm{~mm} \mathrm{Hg}$ were started. Q was gradually increased to $100 \mathrm{~mL} / \mathrm{kg}$ (body wt) $\cdot \min$ over 20$40 \mathrm{~min}$ and at 50-55 min the reservoir was raised so that $\mathrm{Pla}=$ $5 \mathrm{~mm} \mathrm{Hg}$. After a further stabilization period $(\sim 5 \mathrm{~min})$, arterial then venous occlusions were performed as described below. The lungs were then ventilated with the hypoxic gas mixture and after 20-25 min (i.e. when Ppa was stable) the occlusions were repeated. In the 13 preparations in which indomethacin was added after control studies, an additional 20-min stabilization period was allowed before repeating hyperoxic and hypoxic occlusions as in the controls.

Occlusion technique. All occlusions were performed with the ventilator off at end expiration, so that Pla $(5 \mathrm{~mm} \mathrm{Hg})$ was greater than Paw ( $3 \mathrm{~mm} \mathrm{Hg}$ ) (i.e. zone III conditions). The arterial occlusions were accomplished by diverting the flow from the pulmonary artery to a bypass circuit. The occluder was a plexiglass mechanical slide valve that was well lubricated so that occlusions were essentially instantaneous $(<50 \mathrm{~ms})$. After $Q$ at $100 \mathrm{~mL} / \mathrm{kg} \cdot \mathrm{min}$ had been established and Ppa was stable, paper speed was increased to $50 \mathrm{~mm} / \mathrm{s}$ and an inflow occlusion was performed. After $\sim 3 \mathrm{~s}$, the pulmonary artery pressure at $\stackrel{\mathrm{Q}}{=}=0$ $\mathrm{mL} / \mathrm{kg}$ min had reached a stable baseline $(\sim 5 \mathrm{~mm} \mathrm{Hg})$, and the perfusate was redirected through the lungs. Immediately after occlusion the Ppa dropped suddenly to a point Ppa', after which an exponential decline in pressure occurred (Fig. 1). Ppa' was determined by extrapolating the initial part of the exponential

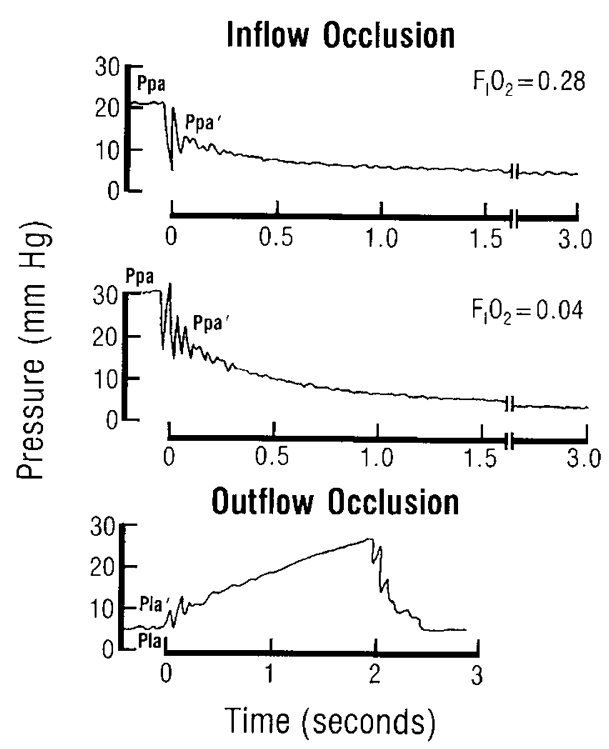

Fig. 1. Tracings of the inflow occlusions at $\mathrm{FIO}_{2}=0.28$ and 0.04 and outflow occlusion at $\mathrm{FIO}_{2}=0.28$. Hypoxia caused an increase in both $\mathrm{Ppa}$ and $\mathrm{Ppa}^{\prime}$, whereas $\mathrm{Pla}$ and $\mathrm{Pla}^{\prime}$ were unchanged. Therefore $\Delta \mathrm{Pm}$ showed the greatest increase while $\Delta \mathrm{Pa}$ increased a little and $\Delta \mathrm{Pv}$ was unchanged.

decline in pressure (i.e. about $300-800 \mathrm{~ms}$ after occlusion) back to time 0 using semilog paper as previously described $(11,15-$ 17). The mean Ppa and $\mathrm{Ppa}^{\prime}$ were determined after two or three occlusions had been performed to ascertain that the results were reproducible. Then, after a stable Ppa at $\stackrel{\mathrm{Q}}{=100 \mathrm{~mL} / \mathrm{kg} \cdot \mathrm{min}}$ was reestablished, the outflow cannula was suddenly occluded. The left atrial pressure rose suddenly to $\mathrm{Pla}^{\prime}$ then more slowly (Fig. 1). Pla' was determined directly from the strip chart recording by finding the intercept of the first part of the slow rise and time $=0$. Again, at least two occlusions were used and the mean $\mathrm{Pla}$ and $\mathrm{Pla}^{\prime}$ determined at each $\mathrm{FIO}_{2}$.

Data analysis. After determining Ppa, $\mathrm{Ppa}^{\prime}, \mathrm{Pla}^{\prime}$, and $\mathrm{Pla}$, at both high and low $\mathrm{FIO}_{2}$, the pressure gradients across each segment of the pulmonary circuit were calculated: $\Delta \mathrm{Pt}=(\mathrm{Ppa}-$ $\mathrm{Pla}), \Delta \mathrm{Pa}=\mathrm{Ppa}-\mathrm{Ppa}^{\prime}, \Delta \mathrm{Pv}=\mathrm{Pla}^{\prime}-\mathrm{Pla}$, and $\Delta \mathrm{Pm}=\Delta \mathrm{Pt}-(\Delta \mathrm{Pa}$ $+\mathrm{Pv})$. The effects of hypoxia and indomethacin on $\Delta \mathrm{Pt}$ and each segment were determined by analysis of variance and LSD at each age. The effect of age on total hypoxic reactivity was determined by one-way analysis of variance and LSD for control and indomethacin-treated lungs. The effect of indomethacin on the change in hypoxic response with age was evaluated by three way analysis of variance and LSD. All results are expressed as means $\pm \mathrm{SE}$ and were considered significant at $p \leq 0.05$.

\section{RESULTS}

The mean hematocrit (15.7-17.5\%), peak Paw (10-12.5 mm $\mathrm{Hg}$ ), and perfusate temperature $\left(38.6-39.1^{\circ} \mathrm{C}\right)$ did not differ among groups. The tidal volumes were slightly lower in the oldest lambs $(14.2-14.5 \mathrm{~mL} / \mathrm{kg})$ when compared to the youngest lambs $(15.4-16.4 \mathrm{~mL} / \mathrm{kg})(p=0.05)$. The weight of the lambs increased with age, but were similar between groups at every age. Blood gas results are shown (Table 1).

Hypoxia caused a significant increase in the total pressure gradient $(\Delta \mathrm{Pt})$ in control lungs of 2-wk and 1-mo-old lambs and at all ages in the indomethacin-treated lungs (Table 2). The pressure gradients across each segment are shown in Figures 2. In the older controls and at all ages in indomethacin-treated lungs, both $\Delta \mathrm{Pa}$ and $\Delta \mathrm{Pm}$ increased with hypoxia (Fig. $2 A$ and $B$ ). However, the absolute value of $\Delta \mathrm{Pm}$ was greater than $\Delta \mathrm{Pa}$ during hypoxia, but less than $\Delta \mathrm{Pa}$ at an $\mathrm{FIO}_{2}$ of 0.28 . Moreover, the relative contribution of $\Delta \mathrm{Pm}$ to the total pressure gradient 
Table 1. Blood gas results*

\begin{tabular}{lclcc}
\hline \multicolumn{1}{c}{ Age } & $\mathrm{pH}$ & $\begin{array}{c}\mathrm{PCO}_{2} \\
\text { controls }\end{array}$ & $\mathrm{PO}_{2}(\mathrm{H})$ & $\mathrm{PO}_{2}(\mathrm{~L})$ \\
\hline $6-12 \mathrm{~h}$ & $7.40 \pm 0.02$ & $31 \pm 1.4$ & $166 \pm 5$ & $30 \pm 1.4$ \\
$2-4 \mathrm{~d}$ & $7.39 \pm 0.05$ & $35 \pm 5.3$ & $157 \pm 18$ & $30 \pm 5.4$ \\
$2 \mathrm{wk}$ & $7.38 \pm 0.04$ & $35 \pm 1.0$ & $151 \pm 12$ & $34 \pm 6.8$ \\
$1 \mathrm{mo}$ & $7.39 \pm 0.03$ & $33 \pm 4.8$ & $160 \pm 19$ & $31 \pm 6.0$ \\
& & & \\
& & & \\
$6-12 \mathrm{~h}$ & $7.38 \pm 0.04$ & $33 \pm 2.7$ & $158 \pm 8$ & $28 \pm 2.0$ \\
$2-4 \mathrm{~d}$ & $7.37 \pm 0.04$ & $35 \pm 3.2$ & $155 \pm 9$ & $32 \pm 4.0$ \\
$2 \mathrm{wk}$ & $7.39 \pm 0.05$ & $35 \pm 1.0$ & $154 \pm 11$ & $33 \pm 8.8$ \\
$1 \mathrm{mo}$ & $7.40 \pm 0.03$ & $32 \pm 2.0$ & $162 \pm 13$ & $30 \pm 5.5$ \\
\hline
\end{tabular}

* There were no differences within or between ages in mean $\mathrm{pH}$, mean $\mathrm{PCO}_{2}$ or mean $\mathrm{PO}_{2}(\mathrm{~mm} \mathrm{Hg})$ at each $\mathrm{FiO}_{2}(\mathrm{H}=0.28, \mathrm{~L}=0.04)$.

Table 2. Total pressure gradients $(\Delta P t)$

\begin{tabular}{lccccc}
\hline & \multicolumn{2}{c}{ Control } & & \multicolumn{2}{c}{ Indomethacin } \\
\cline { 2 - 3 } \cline { 5 - 6 } Age & 0.28 & 0.04 & $\mathrm{FIO}_{2}$ & 0.28 & 0.04 \\
\hline $6-12 \mathrm{~h}$ & $10.7 \pm 2.0$ & $14.3 \pm 2.1$ & & $14.2 \pm 2.5^{*}$ & $35.1 \pm 5.3$ \\
$2-4 \mathrm{~d}$ & $12.0 \pm 2.0$ & $18.3 \pm 2.9$ & & $18.7 \pm 1.1^{*}$ & $37.4 \pm 3.5$ \\
$2 \mathrm{wk}$ & $11.9 \pm 2.4^{*}$ & $20.0 \pm 2.4$ & & $12.4 \pm 1.4^{*}$ & $28.6 \pm 1.6$ \\
$1 \mathrm{mo}$ & $10.0 \pm 1.3^{*}$ & $19.9 \pm 2.3$ & & $10.8 \pm 1.3^{*}$ & $29.2 \pm 2.8$ \\
\hline
\end{tabular}

* Hypoxia increased $\Delta \mathrm{Pt}(\mathrm{mm} \mathrm{Hg})$ at the two older ages in control lungs and all ages in indomethacin treated lungs $(p<0.05)$. Indomethacin accentuated hypoxic $\Delta \mathrm{Pt}$ at all ages $(p<0.05)$.

rose during hypoxia, whereas the contribution of $\Delta \mathrm{Pa}$ to $\Delta \mathrm{Pt}$ remained largely unchanged. Therefore, the predominant hypoxic response appeared to occur within $\Delta \mathrm{Pm}$. Hypoxia had no effect on $\Delta \mathrm{Pt}$ or any segment in the 6- to 12 -h-old control group (Table 2, Fig. 2). In the 2- to 4-d-old control group the response of $\Delta \mathrm{Pt}$ and $\Delta \mathrm{Pm}$ approached but did not reach statistical significance $(p=0.07)$. Hypoxia had no effect on $\Delta \mathrm{Pv}$ in any group except the oldest where a physiologically small (but statistically significant) decrease in pressure gradient was seen in both control and indomethacin-treated lungs (Fig. 2C).

At all ages indomethacin caused a significant accentuation of $\Delta \mathrm{Pt}$ during hypoxia (Table 2). This was due to a striking increase in the hypoxic responses of $\Delta \mathrm{Pm}$ (Fig. $2 B)$ at all ages $(p<0.05)$. In the two younger age groups an accentuation of the hypoxic responses of $\Delta \mathrm{Pa}$ (Fig. $2 A)$ was also seen $(p<0.05)$. Indomethacin had no effect on the responses of $\triangle \mathrm{Pa}$ in older lambs or on the responses of $\Delta \mathrm{Pv}$ at any age.

The effects of indomethacin on age-dependent changes in the hypoxic responses of each segment were determined by threeway analysis of variance (between factors: age and indomethacin; within factor: inspired oxygen tension). Indomethacin significantly altered the effect of age on the response of $\triangle \mathrm{Pm}$ (Fig. $2 B$; $p=0.05, \mathrm{LSD}=3.7$ ). In controls the response was greater in lungs of the 1-mo-old group than the 6- to 12-h group, whereas after indomethacin treatment the response was greater in the lungs of the 6- to 12-h-old than either the 2-wk or 1-mo-old groups. In contrast there was neither an age-dependent increase nor decrease in the responses of $\Delta \mathrm{Pa}$ or $\Delta \mathrm{Pv}$ under control or indomethacin-treated conditions (Figs. $2 A$ and $C$ ).

When total hypoxic reactivity (defined as the change in total pressure gradient between an $\mathrm{FIO}_{2}$ of 0.28 and 0.04 ) was considered, indomethacin did not reverse the effects of age. One way analysis of variance showed that in controls total hypoxic reactivity was greater in the 1 -mo group $(9.9 \pm 1.3 \mathrm{~mm} \mathrm{Hg})$ compared with the 6- to 12 -h group $(3.6 \pm 1.3 \mathrm{~mm} \mathrm{Hg})(p=0.05$, $\mathrm{LSD}=$ 5.9). However, the decrease in hypoxic reactivity over the four ages studied in indomethacin-treated lungs did not reach statistical significance.

The control lungs were all examined in a similar manner in
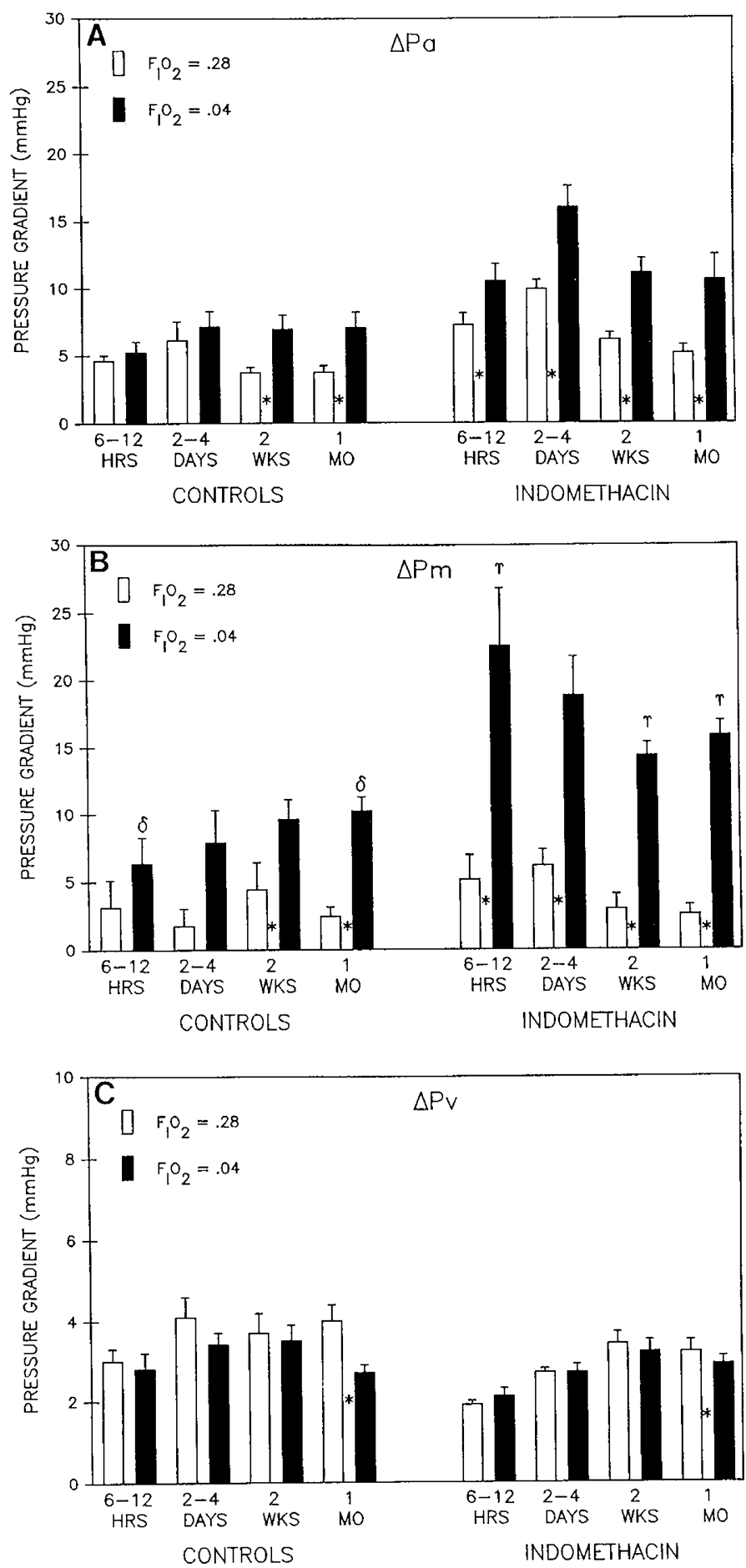

Fig. 2. Effects of hypoxia and indomethacin on $\triangle \mathrm{Pa}(A), \Delta \mathrm{Pm}(B)$, and $\Delta \mathrm{Pv}(C)$ at all ages. Hypoxia caused an increase in $\Delta \mathrm{Pa}$ and $\Delta \mathrm{Pm}$ in older controls and indomethacin-treated lungs of all ages and a decrease in $\Delta \mathrm{Pv}$ in the oldest groups $\left({ }^{*} p<0.05\right.$, all results are mean $\left.\pm \mathrm{SE}\right)$. In $\triangle \mathrm{Pm}$, the hypoxic response of controls was less in the 6- to $12-\mathrm{h}$ than the 1-mo group $(\delta)$, but greater in the 6 - to 12 -h than either the 2 -wk or 1 mo group after indomethacin $(\gamma)$. Indomethacin accentuated the hypoxic response of $\Delta \mathrm{Pa}$ in the 6- to $12-\mathrm{h}$ and 2- to 4-d groups and of $\Delta \mathrm{Pm}$ at all ages.

this study, but two approaches were used in the indomethacin groups. In 13 of 26 the indomethacin was added after a control study was performed whereas in the other 13 it was added at the beginning of the experiment. With both techniques, indomethacin significantly accentuated the hypoxic response (hypoxic $\Delta \mathrm{Pt}$ controls $=18.5 \pm 1.2 \mathrm{~mm} \mathrm{Hg}, \Delta \mathrm{Pt}$ indomethacin at start $=35.9$ 
$\pm 2.7 \mathrm{~mm} \mathrm{Hg}, \Delta \mathrm{Pt}$ indomethacin in the middle $=28.3 \pm 1.4$ $\mathrm{mm} \mathrm{Hg}$ ). Inasmuch as the pressures were not significantly higher in the group in which indomethacin was added at the start, compared with those in which it was added in the middle, we lumped all indomethacin-treated lungs together.

\section{DISCUSSION}

In our study we used an inflow-outflow occlusion technique to show that the pulmonary vascular response to hypoxia occurred predominantly in the middle segment in in situ isolated newborn lamb lungs. A smaller, but significant response also occurred in the upstream segment (Fig. 2). These data are consistent with similar studies in mature dogs (15) and pigs (16), as well as with a recent study in fetal and newborn lambs (11). The anatomic limits of the middle segment have not been established. Tod et al. (17) performed inflow-outflow occlusions after embolizing mature pig lungs with glass beads. They found that the upstream gradient did not increase despite embolization with beads as large as $2-3 \mathrm{~mm}$ in diameter suggesting that $\Delta \mathrm{Pm}$ might include arterioles as large as $3 \mathrm{~mm}$ in diameter (17). However, Michel et al. (18) showed in dogs that pressures measured in small arterioles with $1.2-\mathrm{mm}$ lumen catheters were greater than those defined as $\mathrm{Ppa}^{\prime}$ by the occlusion technique, suggesting that the upstream limit of $\Delta \mathrm{Pm}$ is arterioles under $1.2 \mathrm{~mm}$ in diameter. Because the occlusion technique relies on differences in compliance between small vessels and larger veins to define the downstream limits of $\Delta \mathrm{Pm}$, small veins also likely reside within $\Delta \mathrm{Pm}$. Using small catheters in veins as they did on the arteriolar side, Michel et al. (18) showed that the veins within $\Delta \mathrm{Pm}$ were also likely less than $1.2 \mathrm{~mm}$ in diameter. In a recent abstract, Hakim and Kelly (19) have reported that the limits of $\Delta \mathrm{Pm}$ are arterioles and veins that are less than $0.9 \mathrm{~mm}$ in diameter by small catheter studies but larger than $60 \mu \mathrm{m}$ in diameter as determined by micropuncture (19). These studies suggest that small arterioles, veins, and capillaries all likely lie within $\Delta \mathrm{Pm}$. We are therefore unable to state which vessels are the anatomic effectors of HPV in the newborn lamb lungs studied here.

Others have made use of the changes in HPV which occur during the newborn period to try to define the anatomic site of HPV through various other techniques. However, there is little agreement among these studies. The vigor of HPV was positively correlated with peripheral extension of arteriolar muscularization in piglets aged 2-4 wk to $6 \mathrm{mo}$, supporting the hypothesis that small arterioles are the site of $\operatorname{HPV}(9,10)$. Other evidence for this includes an angiographic study in mature cats showing that arterioles $300 \mu \mathrm{m}$ in diameter were the vessels most responsive to acute hypoxia (20). However, hypoxia was shown to increase lymph flow in newborn lambs as compared with older sheep suggesting that (at least in newborns) the site of HPV is on the venous side of the circuit, downstream from permeable capillaries (12). Hazinski and Kennedy (13) also supported a primary role for capillaries or veins in their study showing that hypoxia increased pulmonary capillary wedge pressure, but not left atrial pressure. The micropuncture technique has also been used in newborn animals. This technique involves determining the pressures within small (20-60 or $80 \mu \mathrm{m}$ diameter) arterioles and venules visualized on the pleural surface of the lung (21-23). Inasmuch as pulmonary artery and left atrial pressures are also measured, gradients between the pulmonary artery and small arterioles (upstream segment), small arterioles and small veins (microcirculation), and small veins and left atrium (downstream segment) can be identified. Using this technique Fike et al. (21) have shown that the upstream segment is the predominant site of HPV in newborn rabbits. However, Raj and Chen (23) showed that in lambs, the pressure gradients across both the upstream and downstream segments increased in response to hypoxia.

Although the micropuncture and lymph flow studies excluded a major role for the microcirculation in HPV in newborn lambs, neither technique identifies the size of vessels in the upstream or downstream segments responsible for HPV. The segment we have defined as $\Delta \mathrm{Pm}$ likely includes a portion of the upstream and downstream segments as defined by micropuncture. Furthermore, $\Delta \mathrm{Pm}$ likely includes the small arterioles $(<500 \mu \mathrm{m}$ diameter) which undergo vascular muscular involution during early development (1) and the venules downstream from the permeable capillaries (12). Identification of the anatomic site of HPV in the newborn lamb may be better accomplished in the future by combining micropuncture, occlusion, and other techniques such as small catheter pressure measurements with detailed morphologic data.

In our study, we also examined the effect of the cyclooxygenase inhibitor, indomethacin, on hypoxic reactivity and the distribution of vascular resistances during development. As seen in previous studies of isolated lungs of mature (24), newborn (25), and fetal animals (25), cyclooxygenase inhibition accentuated the hypoxic response at all ages (Table 2). In the 2-wk and 1mo-old groups this was due solely to an increase in the hypoxic response of the middle segment (Fig. $2 B$ ). However, in the younger age groups, the hypoxic responses of both the upstream and middle segments were accentuated by indomethacin (Fig. 2 $A$ and $B$ ). This apparent change in site of dilator PG activity and the marked attenuation of HPV in isolated lungs of controls at 6-12 $\mathrm{h}$ and 2-4 d of age, confirmed our previous observation that dilator PG appear to have a greater effect on isolated lungs in younger than older newborn lambs.

Given the difficulties in determining and interpreting PG concentrations in serum (8), we did not measure PG concentrations in this study. Instead we assumed that the accentuation of HPV by indomethacin seen in our study was due to the inhibition of production of any, or all, potential dilator PG. These include $\mathrm{PGI}_{2}$ which has been shown to increase in response to HPV in both newborn and mature animals $(24,26)$, as well as $\mathrm{PGD}_{2}(27)$ and the PGE series (28) that cause vasodilation in young newborns. Whether the greater attenuation of HPV and the accentuation of $\Delta \mathrm{Pa}$ as well as $\Delta \mathrm{Pm}$ in lungs of younger lambs in our study were due to increased concentrations of specific dilator $\mathrm{PG}$ or altered vascular sensitivity to $P G$ in the younger lambs remains to be addressed. It is also possible that indomethacin may have acted by a noncyclooxygenase-dependent mechanism. However, other cyclooxygenase inhibitors such as meclofenamate have been shown to accentuate HPV in isolated lungs (24). Furthermore, although it has been argued that cyclooxygenase inhibition might divert arachidonic acid to the leukotriene pathway resulting in increased production of vasoconstrictor leukotrienes (29); in both newborn lambs (30) and mature sheep (31) the increase in PVR normally seen after arachidonic acid administration was prevented by pretreatment with indomethacin, making this explanation unlikely.

In this study, the total hypoxic response and the hypoxic response of the middle segment increased between $6-12 \mathrm{~h}$ and 1 mo of age in control lungs (Fig. 2, Table 2). This was consistent with the age-dependent increase in HPV previously seen in isolated lungs of rabbits $(6,7)$ and lambs $(8,11)$. Indomethacin blocked the increase in total hypoxic reactivity in this study and the hypoxic response of $\Delta \mathrm{Pm}$ (i.e. that segment most responsive to hypoxia) decreased between $6-12 \mathrm{~h}$ and $2 \mathrm{wk}$ or 1 mo once the modulating influence of dilator PG was removed (Fig. 2, Table 2). This decrease in hypoxic response with age was similar to that seen in intact calves (3), pigs (4), and sheep (5). A possible explanation for this effect of cyclooxygenase inhibition is that in control isolated lungs the manipulation involved in the preparation caused an increase in PG release resulting in greater modulation of HPV than seen in intact animals. Indirect support for this idea includes the observation that rapid ventilatory rates (32) and rapid alteration in vascular pressures or flow rates (33) caused an increase in $\mathrm{PGI}_{2}$ production. That isolated lungs may produce more dilator $\mathrm{PG}$ is also supported by the findings that meclofenamate did not accentuate HPV in intact piglets between 5 and $88 \mathrm{~d}$ of life (4) and in intact 2- to 3-wk-old lambs, 
indomethacin had only a transient effect on hypoxic vasoreactivity (34). Nonetheless, the manipulation of the lungs in our study was similar at all ages. Therefore, the greater attenuation of HPV in control isolated lungs of younger rather than older lambs likely represented a greater capacity to modulate HPV in the younger animals.

In summary, we have identified the compliant middle segment as the predominant site of HPV and the site most affected by indomethacin in isolated lungs of newborn lambs. The hypoxic response of this segment rose between $6-12 \mathrm{~h}$ and 1 mo of age in controls, but after the possibly confounding influence of dilator PG was removed, the response decreased with age. The upstream gradient showed a significant, but lesser, response to hypoxia, and in younger lambs the response was accentuated by indomethacin. However, there was neither an age-dependent increase nor decrease in the hypoxic responses of $\Delta \mathrm{Pa}$ or $\Delta \mathrm{Pv}$. As discussed earlier the anatomic limits of the middle segment are not certain, thus we cannot know which vessels are responsible for HPV. However, we find it interesting to speculate that if arteriolar medial involution in the growing lamb is similar to that described in the piglet $(1,9)$, then the decrease in the hypoxic response of $\Delta \mathrm{Pm}$ over the 1 st mo of age seen after indomethacin administration would parallel the decrease in arteriolar muscularization. Such a finding would support the possibility that small arterioles play a major role in HPV. Future studies aimed at more directly identifying the anatomic site of HPV within $\triangle \mathrm{Pm}$ and identifying the dilator PG modulating HPV during development must be undertaken.

Acknowledgments. The authors thank Ms. T. O'Riley, N. Corman, and S. Watters for technical help and Ms. S. Lapointe and J. de Foy for secretarial assistance. Thanks also to Mary Tod, Ph.D. for continued long distance collaboration.

\section{REFERENCES}

1. Cassin S, Dawes GS, Mott JC, Ross BB, Strang LB 1964 The vascular resistance of the foetal and newly ventilated lung of the lamb. J Physiol 171:61-79

2. Haworth SG, Hislop AA 1981 Adaptation of the pulmonary circulation to extra-uterine life in the pig and its relevance to the human infant. Cardiovasc Res 15:108-119

3. Reeves JT, Leathers JE 1964 Circulatory changes following birth of the calf and the effect of hypoxia. Circ Res 15:343-354

4. Redding GJ, McMurtry I, Reeves JT 1984 Effects of meclofenamate on pulmonary vascular resistance correlate with postnatal age in young piglets. Pediatr Res 18:579-583

5. Custer JR, Hales CA 1985 Influence of alveolar oxygen on pulmonary vasoconstriction in newborn lambs versus sheep. Am Rev Respir Dis 132:326331

6. Fike CD, Hansen TN 1987 Hypoxic vasoconstriction increases with postnatal age in lungs from newborn rabbits. Circ Res 60:297-303

7. Owen-Thomas JB, Reeves JT 1969 Hypoxia and pulmonary arterial pressure in the rabbit. J Physiol 201:665-672

8. Gordon JB, Tod ML, Wetzel RC, McGeady ML, Adkinson NF, Sylvester JT
1988. Age-dependent effects of indomethacin on hypoxic vasoconstriction in neonatal lamb lungs. Pediatr Res 23:580-584

9. Rendas A, Branthwaite M, Lennox S, Reid L 1982 Response of the pulmonary circulation to acute hypoxia in the growing pig. J Appl Physiol 52:811-814

10. Rendas A, Branthwaite M, Reid L 1978 Growth of pulmonary circulation in normal pig - structural analysis and cardiopulmonary function. J Appl Physiol 45:806-817

11. Tod ML, Sylvester JT 1989 Distribution of pulmonary vascular pressure as a function of perinatal age in lambs. J Appl Physiol 66:79-87

12. Bressack MA, Bland RD 1980 Alveolar hypoxia increased lung fluid in unanesthetized newborn lambs. Circ Res 44:111-116

13. Hazinski TA, Kennedy KA 1987 Alveolar hypoxia increases small pulmonary wedge pressure in awake young lambs. Pediatr Res 22:679-682

14. Dawson CA 1984 Role of pulmonary vasomotion in physiology of the lung. Physiol Rev 64:544-616

15. Hakim TS, Michel RP, Minimi H, Chang HK 1982 Site of pulmonary hypoxic vasoconstriction studied with arterial and venous occlusion. J Appl Physiol 54:1298-1302

16. Rock P, Patterson GA, Permutt S, Sylvester JF 1985 Nature and distribution of vascular resistance in hypoxic pig lungs. J Appl Physiol 59:1891-1901

17. Tod ML, McGeady JL, Rock P, Sylvester JT 1987 Effects of arterial ligation and embolization on pulmonary vascular pressure distribution. J Appl Physiol 63:1887-1395

18. Michel RP, Hakim TS, Chang HK 1984 Pulmonary arterial and venous pressures measured with small catheters in dogs. J Appl Physiol 57:309-314

19. Hakim TS, Kelly S 1989 Occlusion pressure versus micropipette pressures and small catheter pressures. FASEB J 3:A979(abstr)

20. Shirai M, Sada K, Ninomiya I 1986 Effects of regional alveolar hypoxia and hypercapnia on small pulmonary vessels in cats. J Appl Physiol 61:440-448

21. Fike CD Lai-Fook SJ, Bland RD 1988 Microvascular pressures during hypoxia in isolated lungs of newborn rabbits. J Appl Physiol 65:283-287

22. Raj Ju, Chen P 1986 Microvascular pressure measured by micropuncture in isolated lamb lungs. J Appl Physiol 61:2194-2201

23. Raj JU, Chen P 1986 Micropuncture measurement of microvascular pressures in isolated lamb lungs during hypoxia. Circ Res 59:398-404

24. Voelkel NF, Gerber JG, McMurtry IF, Ries AS, Reeves JT 1981 Release of vasodilator prostaglandin, $\mathrm{PGI}_{2}$, from isolated rat lung during vasoconstriction. Circ Res 48:207-213

25. Tyler T, Wallis R, Leffler C, Cassin S 1975 The effects of indomethacin on the pulmonary vascular response to hypoxia in the premature and mature newborn goats. Proc Soc Exp Biol Med 150:695-698

26. Green RS, Leffler CW 1984 Hypoxia stimulates prostacyclin synthesis by neonatal lungs. Pediatr Res 18:832-835

27. Drummond WH, Carter RL 1987 Cardiac depressant and circulatory effects of prostaglandin $\mathrm{D}_{2}$ in developing lambs. Am J Physiol 252:H374-H383

28. Cassin S, Tyler T, Leffler C, Wallis R 1979 Pulmonary and systemic vascular response of perinatal goats to prostaglandins $E_{1}$ and $E_{2}$. Am $J$ Physiol 236:H828-H832

29. Kuehl FA, Dougherty HW, Ham EA 1984 Interactions between prostaglandins and leukotrienes. Biochem Pharmacol 33:1-5

30. Tod ML, Cassin S 1984 Perinatal pulmonary responses to arachidonic acid during normoxic and hypoxia. J Appl Physiol 57:977-983

31. Meyrick B, Niedermeyer ME, Ogletree ML, Brigham KL 1985 Pulmonary hypertension and increased vasoreactivity caused by repeated indomethacin in sheep. J Appl Physiol 59:443-452

32. Wetzel RC, Gordon JB, Gregory TJ, Gioia FR, Adkinson NF, Sylvester JT 1985 High frequency ventilation attenuation of hypoxic pulmonary vasoconstriction. Am Rev Respir Dis 132:99-103

33. Van Grondelle A, Worthen GS, Ellis D, Mathias MM, Murphy RC, Strife RJ, Reeves JT, Voelkel NF 1984 Altering hydrodynamic variables influences $\mathrm{PGI}_{2}$ production by isolated lungs and endothelial cells. J Appl Physiol 57:388-395

34. Lock JE, Olley PM, Soldin S, Coceani F 1980 Indomethacin-induced pulmonary vasoconstriction in the conscious newborn lamb. Am J Physiol 238:H639-H651 